\title{
Improving the Gut Microbiota with Probiotics and Faecal Microbiota Transplantation
}

\author{
Yogita M. Patil ${ }^{1}$, Rajashree B. Patwardhan ${ }^{2 *}$ (D) and Pragati S. Abhyankar ${ }^{2}$ (D) \\ ${ }^{1}$ Department of Microbiology, PDEA'S Waghire College, Saswad, Pune - 412 301, Maharashtra, India. \\ ${ }^{2}$ Department of Microbiology, Haribhai V. Desai College of Arts, Science and Commerce, Pune- 411002 , \\ Maharashtra, India.
}

\begin{abstract}
Probiotics are "live strains of strictly selected microorganisms which, when administered in adequate amounts, confer a health benefit on the host". After birth, our intestine is colonized by microbes like Escherichia coli, Clostridium spp., Streptococcus spp., Lactobacillus spp., Bacteroides spp., and Bifidobacterium spp. Our intestine is an extremely complex living system that participates in the protection of host through a strong defence against external aggregations. The microbial ecosystem of the intestine includes many native species of Bacteroides and Firmicutes that permanently colonize the gastrointestinal tract. The composition of flora changes over time depending upon diet and medical emergencies which leads to the diseased condition. Probiotics exert their mode of action by altering the local environment of the gut by competing with the pathogens, bacteriocins production, $\mathrm{H}_{2} \mathrm{O}_{2}$ production etc. Obesity is one of the major health problems and is considered as the most prevalent form of inappropriate nutrition. Probiotics like Lactobacillus Sp., Bifidobacterium Sp., Streptococcus Sp. are successfully used in the treatment of obesity proved in clinical trials. Faecal microbiota transplant (FMT), also known as a stool transplant, is the process of transplantation of Faecal bacteria from a healthy donor into a recipient's gut to restore normal flora in the recipient. The therapeutic principle on which FMT works is microbes and their functions and metabolites produced by them which are used to treat a variety of diseases. The present review focuses on the role of gastrointestinal microbiome, probiotic selection criteria, their applications and FMT to treat diseases.
\end{abstract}

Keywords: Probiotics, Obesity, Microbial ecosystem, Faecal microbiota transplantation

*Correspondence: dr.rbpatwardhan@gmail.com; +91 9422015045

(Received: March 15, 2021; accepted: August 07, 2021)

Citation: Patil YM, Patwardhan RB, Abhyankar PS. Improving the Gut Microbiota with Probiotics and Faecal Microbiota Transplantation. J Pure Appl Microbiol. 2021; 15(3):1111-1124. doi: 10.22207/JPAM.15.3.53

(C) The Author(s) 2021. Open Access. This article is distributed under the terms of the Creative Commons Attribution 4.0 International License which permits unrestricted use, sharing, distribution, and reproduction in any medium, provided you give appropriate credit to the original author(s) and the source, provide a link to the Creative Commons license, and indicate if changes were made. 


\section{INTRODUCTION}

In today's era focus is on functional foods for health enrichment with minimum efforts. Interest in self-care and integrative medicine, coupled with foods that promote health, apart from providing basic nutrition has emerged in recent times. Historically, yoghurt is probably the oldest example of fermented food which was used to support intestinal and overall health. In ancient Indian societies, it was a common practice to consume a yogurt drink called Lassi beforedinner and a small serving of curd at the end of meal. These Indian traditions assumed of using sour milk are perhaps the earliest examples of a probiotic delivery system to our body. The origin of word 'Probiotic' is traced to Greek language, 'pro bios' which means 'for life'. Its opposite 'antibiotic' is more familiar meaning 'against life'. Probiotics were first described in 2002 by the authorities from the Food and Agriculture Organization of the United Nations and the World Health Organization. The definition was revised by the International Scientific Association in $2013^{1}$. The definition reveals that, "probiotics are live strains of strictly selected microorganisms which, when administered in adequate amounts, confer a health benefit on the host." The intestinal tract of new-born is sterile at birth, with time and age it gets colonized by number of organisms from breast milk, formula fed milk, mother's vagina, diet, environment etc. A vast number of factors affect colonization of intestine by bacteria. The very first organisms to colonize in the new-born are Escherichia coli, Clostridium spp., Streptococcus spp., Lactobacillus spp., Bacteroides spp., and Bifidobacterium spp. Bifidobacterium which colonizes in highest numbers gets excreted in faeces of breast-fed infants ${ }^{2}$. The composition of flora changes overtime depending upon diet and medical emergencies. The number of bacteria present in large intestine is upto $10^{11}$ colony-forming units/g. The healthful human gut is conquered by Bacteroides, Firmicutes and Actinobacteria, each comprising a unique bacterial composition of the stool ${ }^{3}$. The gut microflora plays a significant role in human well-being, not only due to its contribution in the digestion progression but also for its critical role in the maturity of the gut and the immune system. The human gastrointestinal tract (GIT) comprises an extraordinarily complex and active microbial community which in particular for every individual depends on environmental and genetic factors ${ }^{4}$. The gastrointestinal flora is increasingly being used for prevention and treatment of several disorders like lactose intolerance, allergies, colon cancer, Irritable bowel syndrome (IBS), Osteoarthritis and diseases like Clostridium difficile (CD) infection and diarrhoea ${ }^{5-7}$. Knight and his coworkers showed presence of probiotics in faeces after three days of oral administration therapy with Synbiotic 2000 Forte which is a mixture of probiotics able to survive in the stomach and gut. Synbiotic 2000 Forte consists of combination of $10^{11}$ colony forming units of each of four probiotics, Lactobacillus paracasei $25 \%$, L. plantarum $25 \%$, Leuconostoc mesenteroides 25\%, Pediococcus pentosaceus $25 \%$ with bioactive fibres, oat bran, $2.5 \mathrm{~g}$, pectin, $2.5 \mathrm{~g}$, resistant starch, $2.5 \mathrm{~g}$, inulin, $2.5 \mathrm{~g}$ (total weight, $10 \mathrm{~g})^{8}$.

Faecal microbiota transplant (FMT) is a technique in which Faecal matter from a healthful donor is mixed with saline solution and is placed into a recipient with chronic, serious, or complicated Clostridium difficile (CD) infection. The primary purpose of FMT is to re-establish a healthy microbiota balance that facilitates the resistance to growth of pathogenic bacteria, thus reducing the chance of recurrent colitis and dysentery.

\section{Criteria for selection of Probiotics}

The source of probiotic culture often is of human origin like human faces or breast milk, animal source like fresh raw milk or fermented food. As per the guidelines of FAO/WHO 2002 probiotic tests which are currently used in vitro for screening of cultures are

i. Resistance to gastric acidity

ii. Bile acid resistance

iii. Adherence to mucus and/or human epithelial cells and cell lines

iv. Antimicrobial activity against potentially pathogenic bacteria

v. Capability to reduce pathogen adhesion to surfaces

vi. Bile salt hydrolase activity

vii. Resistance to spermicides (applicable to probiotics for vaginal use)

Probiotics commonly provided through dairy products improve the transit tolerance of bacteria. Other delivery systems for probiotics 
are meat and fish-based products, confectionery, table olives, soya and cereal-containing products, edible spreads, artichokes (European plant) etc. ${ }^{9}$ Artichokes or olives furnish nutrients to enable bacterial survival throughout shelf storage. The mode of action Probiotics is by altering the local environment of the gut, producing antimicrobial compounds like bacteriocins to be used against pathogens. Hence a strict selection criterion is employed to obtain functional probiotic strains. Most of the probiotics are a mixture of strains of Lactobacilli and (or) Streptococci and Bifidobacterium. Some commercial products contain strains in combination with others leading to enhanced effect. The probiotic strain should be of host origin, well characterized, able to colonize by surviving the rigors of the digestive tract and, biologically active against the target as well as stable and flexible for commercial production and distribution ${ }^{10}$.

\section{Desirable Characteristics for Potential Probiotic} Strain

To be defined as probiotic, a microbe must possess a following set of criteria ${ }^{11}$

- Exert a beneficial effect on host

- Nontoxic and non-infective

- Precise taxonomic classification

- Normal inhabitant of species

- Able to survive, proliferate, and having metabolic activity in the target site, which include

- Resistance to gastric and bile salts

- Adherence to intestinal epithelial cell lining

- $\quad$ Capacity to compete with resistant flora

- Produce antimicrobial substances

- Stabilize intestinal microflora

- Acceptable to host's immune response

- In vivo antagonism towards pathogenic bacteria

- Genetically stable

- Amenability of strain

- $\quad$ Stability of desired characteristics during processing, storage, and delivery

- Feasibility at highest population

- Good shelf life in food

- Biosafety, the strain used should belong to, Generally Regarded as Safe (GRAS) category

Bile Tolerance the probiotic strain to be able to resist low $\mathrm{pH}$ due to gastric acid, bile and gastric enzymes. Acid and bile stability are significant among the other criteria used in selection probiotic microbes ${ }^{12}$. The bile salts act as biological detergent which emulsifies and solubilizes fats. This confers powerful antimicrobial properties to bile and plays an significant role in the body's physico-chemical defence system ${ }^{13}$. Probiotics like Lactobacilli ${ }^{14}$, Bifidobacteria $^{15}$, Enterococcus ${ }^{16}$, Saccharomyces ${ }^{17}$ assimilate cholesterol and deconjugate bile acids, leading to a decrease in serum cholesterol. Bile salts are produced in liver from cholesterol and secreted as amino acid conjugates into the duodenum. The exact mechanism by which probiotics lower serum cholesterol is unclear but it is thought that cholesterol elimination from culture media is a result of formation of cholesterol with free bile acids in the media due to activity of bile salt hydrolase enzyme. Enterococcus faecium WEFA23 isolated from human infants has Glycodeoxycholic acid (GDCA) hydrolase activity and cholesterol-removal ability in an environment containing $3 \%$ bile salt ${ }^{18}$.

\section{Acid Tolerance}

The initial screening of probiotics includes tolerance of cultures to gastric acid. Acid tolerance of probiotics is also essential for production of probiotic products like fermented foods. Hence acid tolerance is primarily important in screening for probiotic cultures ${ }^{12}$. A healthy adult human stomach secretes about 1.5 litres of gastric acid daily. To survive in the stomach, probiotic strains must bear the acidic conditions of the stomach $\mathrm{pH}$ 1.5 to 3.5. The presence of prebiotic substances carried by artichokes or olives such as inulin, contribute efficiently to favour the growth of indigenous lactobacilli and/or bifidobacteria ${ }^{9}$. Artichokes when preserved in brine of $\mathrm{pH} 3.5$, enriched with L. plantarum ITM21B or L. paracasei IMPC2, no considerable decrease in the bacterial population was observed for either strain after 30 days of storage ${ }^{9}$. In order to survive in the stomach, probiotic strains must tolerate the acidic $\mathrm{pH}$ of the stomach i.e. about 1.5 to 3.5 . It is assumed that acid tolerance of Bifidobacteria depends on $\mathrm{H}^{+}$-ATPase activity ${ }^{19}$. B. animalis and $B$. lactis are more acid tolerant among the Bifidobacteria ${ }^{20}$ having higher $\mathrm{H}^{+}$-ATPase activity ${ }^{21}$.

Survival in gastrointestinal tract requires 


\section{Antipathogenic activity}

One selection criterion for probiotics is the production of antimicrobial substances, which exert a beneficial effect on host. Lactic acid and acetic acid producing probiotics decrease the $\mathrm{pH}$ of the lumen creating unfavorable conditions for pathogens ${ }^{22}$. Along with bacteriocins, LAB produce organic acids, such as lactic and acetic acids, hydrogen peroxide, or diacetyl having antimicrobial potential ${ }^{23}$. Probable mechanism by which probiotics exhibit antipathogenic effect is shown in Fig. 1. Other antimicrobial compounds secreted by LAB and Bifidobacteria against dermal pathogen Staphylococcus aureus are lactic acid, acetic acid, hydrogen peroxide, and diacetyl ${ }^{24}$. Thus, probiotic strains that are able to colonize in the digestive tract play a significant role in the release of antimicrobial compounds which, by their highly inhibitory action, regulates the composition of normal flora in the digestive tract. An imbalance in normal intestinal flora is an obvious reason of establishment and growth of enteropathogens like Salmonella, Campylobacter, Escherichia coli and others. A commercially available bifidus yoghurt and oral preparation of Bifidobacteria is used to eliminate Campylobacterium jejuni from stools of children suffering from enteritis ${ }^{25}$. Bifidobacterium animalis lactis BB-12 and Enterococcus faecium used as adjuvant in therapy, are clinically proven to eradicate Helicobacter pylori ( $\mathrm{Hp}$ ) infection with reduction in incidences side effects, mainly diarrhea ${ }^{26}$. Probiotics also help us in fighting against common food borne pathogens like Salmonella

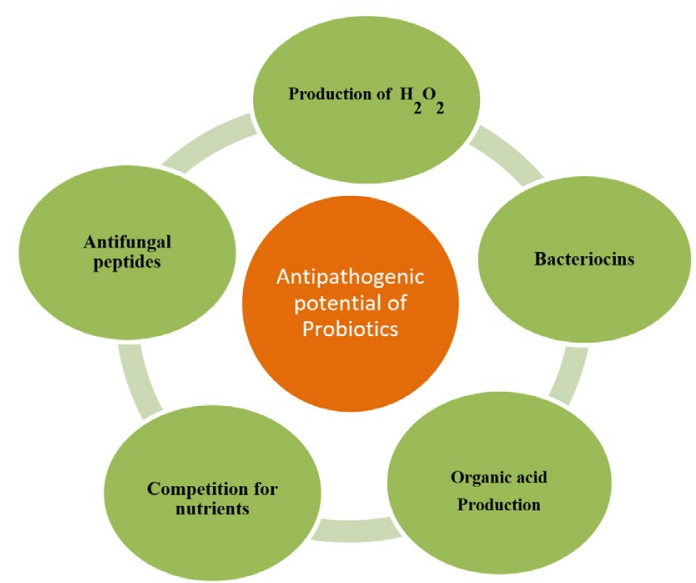

spp., S. aureus, Listeria monocytogenes, E. coli, Shigella spp., Campylobacter spp. along with, species of Pseudomonas, Bacillus and Serratia. ${ }^{27-29}$. Adherence to mucus and human epithelial cells and cell lines

Capability to adhere to human intestinal surfaces is one of the key selection criteria for probiotic bacteria. Adhesion of probiotics to intestinal wall helps to maintain normal flora in the gut thus influencing the host's microbial balance and gastrointestinal system. To study in vitro adhesive properties of probiotics enterocyte like Caco- 2 tissue culture cells ${ }^{30}$, intestinal mucus and human ileostomy glycoproteins are currently used $^{31}$. Intestinal mucus protects mucosal lining from microbes, provides initial binding site and matrix on which microbes adhere, also serving as a nutrient source to them. B. longum and $B$. catenulatum adhere to human intestinal mucus and inhibit competitively pathogens like Salmonella enterica serovar typhimurium, $E$. coli, L. monocytogenes, Enterobacter sakazakii, and Clostridium difficile from adhering to human intestinal mucus ${ }^{32}$. L. acidophilus CRL1259L, L. crispatus CRL 1266, L. paracasei CRL 1289 adhere competitively to vaginal epithelial cells (VEC) and exclude urogenital pathogens like $S$. aureus. L. acidophilus 1259 and L. paracasei CRL 1289 competitively excluding Group B Streptococci33. L. delbrueckii spp. bulgaricus (LDB B-30892) substantially lowers the adhesion of $C$. difficile to the human colonic Caco- 2 cells $^{34}$. Live and heat killed strain of $L$. rhamnosus CNCM-I-3698 and $L$. farciminis CNCMI-3699 respectively, are adherent to intestinal matrix models and their high coaggregation property has been proved in vitro which eliminates Campylobacter spp. ${ }^{35}$

In addition to adhesion, another important mechanism for pathogen exclusion by probiotics is aggregation. Probiotics also exert capacity to aggregate among themselves (auto-aggregation), with other probiotics and with pathogens (co-aggregation). Co-aggregation leads to the formation of a protective barrier for intestinal epithelium, inhibiting colonization by harmful pathogens. Measuring co-aggregation of pathogens serves as a preliminary screening to identify potentially probiotic organisms ${ }^{36}$.

Fig. 1. Antipathogenic Potential of Probiotics 


\section{Biosafety}

Probiotics are not under regulation of the US Food and Drug Administration (FDA) as they are considered to be dietary rather than a therapeutic product. They are easily available in market and can be bought without prescription. Probiotics are consumed as health supplements rather than therapy. Some may experience gas and bloating after consumption ${ }^{37}$. With respect to safety consideration of probiotic microorganisms, it is recommended that probiotic microorganisms are strictly free of genetic resistance determinants like plasmid, which encode resistance against clinically used antibiotics ${ }^{38}$. Such probiotic are generally regarded as safe (GRAS) and can be used safely ${ }^{39}$. Available safety data regarding the broad range of probiotic strains added to food or feed are periodically compiled by the European Food Safety Authority (EFSA) ${ }^{40}$.

\section{Health Benefits}

There are numerous health benefits of probiotic organisms. Most probiotic strains of human origin are safe to use because they are commensals and exert rapid effects.

\section{Gut microbiota}

Gut microbiota (GM) is also called as "forgotten organ" which harbours 100 trillion bacteria, (fungi, archaea, and viruses) which are 10 times greater than the number of cells present in human body ${ }^{41}$. Intestine is an enormously multifaceted living system that protects the host strongly against external aggregations. The small intestine harbours a single dense mucus layer. In the colon, mucus is organized into two distinct layers, an outer loose layer, and an inner dense layer that is connected to the epithelium. The fast-increasing facultative anaerobes overgrow microbial community of the small intestine that tolerates the influences of bile acids and antimicrobials. Small intestine of humans contains Proteobacteria and Clostridium species. The cecum and colon of large intestine contains anaerobic fermentative polysaccharide catabolizing anaerobes belonging to families Bacteroidaceae and Clostridiaceae. Dominant organisms in the colon belong to Firmicute families, Lachnospiraceae and Ruminococcaceae. In stomach dominant organisms are Bacteroidetes families, Prevotellaceae, Bacteroidaceae, and Rikenellaceae ${ }^{42}$. As stated above, bacterial population is much higher in the colon as compared to the small intestine. The colon is colonized by bacterial families including Bacteriodaceae, Ruminococcaceae, Prevotellaceae, and Clostridiaceae ( $\left.10^{11}-10^{12} \mathrm{CFU} / \mathrm{ml}\right)$. Indigenous flora of stomach consist of species from the families Lactobacillaceae and Streptococcaceae in the epithelial layer. The gut microflora plays a key role against extrinsic bacteria through resistance to colonization. The homeostasis in gut can be due to dietary changes, antibiotic exposure, infections, disease states, and maturing. Aging was complemented with growing proportion of Bacteroides, Eubacterium and Clostridiaceae. Enterobacteriaceae was augmented in infant and aged people. There is age-related decrease in the performance of gut microbiota, as well as rise of inflammation and diseases, particularly for the aged people older than $90 \mathrm{~s}^{43}$.

FMT (Faecal microbiota transplantation): Faecal microbiota transplant (FMT), also wellknown as stool transplant, is the practice of transplantation of faecal bacteria from a healthful donor into a recipient to reestablish normal flora in recipient ${ }^{44}$. FMT is the known terminology which defines the infusion of distal faecal matter from a healthy donor into the Gastrointestinal tract of a recipient to re-establish healthy intestinal microflora ${ }^{45}$. The therapeutic principle on which FMT works is microbes, their roles and the metabolites formed by them ${ }^{46}$. The criterion of FMT is to improve intestinal imbalance by transporting stool comprising a stable, live, varied, and normal microbial community from a healthy donor or from well-defined colonic bacterial strains ${ }^{46}$. FMT requires restoration of the microflora by establishing healthy bacterial flora via infusion of stool, e.g. via colonoscopy, enema, orogastric tube, or by mouth in the form of a capsule containing freeze-dried material, gained from a healthy donor. The constant antibiotic medication in patients leads to acute damage of normal intestinal microflora. Replacing the entire intestinal flora of recipient by healthy donor flora gets a donor-like flora composition with stabilization of its usefulness in the recipient. With a level of complexity like an organ, the gut is home to a intricate mixture of more than 1000 microbial varieties, which jointly harbour 100 times more genes than the human genome. 
A healthy human gut microbiota comprises of a higher ratio of Bacteroides to Firmicutes and overall higher bacterial diversity ${ }^{47}$. The gastrointestinal microbiome (GIM) may be subject to progressive or dietary compositional variations, antibiotic damage and super infections, like the $C$. diffcile infection (CDI). Changes in diet, administration of particular antibiotics, probiotics, or FMT may be utilized to rebuild dysbiosis or eradicate contagious pathogens, such as $C$. diffcile $e^{45}$. Due to the increase in cases of community and hospital acquired CDI, elevated rates of recurrent CDI (projected 20-30\% after a first and $50-60 \%$ after a third infection), high mortality ( 29,000 deaths annually) in the USA, and the emergency for treatments not involving antibiotics gave birth to microbiome-based remedies $^{48}$. Pseudomembranous colitis (PMC) is a disease of the colon caused due to antibiotics or other agents upsetting the normal intestinal flora. Bacteroides sp. are absent in patient's stool and are present after FMT when PMC is treated with FMT, indicating that colonization with Bacteroides sp. seems to be particularly crucial in maintaining normal bowel movement and increased resistance to Gastrointestinal infections ${ }^{49}$. FMT was first used in 1950 s by Mr. Ben Eiseman to treat his patients with antibiotic associated diarrhoea. Since then, it has been a highly effective strategy for treating $\mathrm{CDI}^{50}$. After being successfully used in treatment of C. difficile, FMT can be used in cure of inflammatory bowel disease (IBD) which is a medical condition accounted as abdominal discomfort or pain and gut dysbiosis without pathological condition ${ }^{51}$. IBD is also a group of immune-mediated diseases mainly denoted by Ulcerative colitis (UC) and Crohn's disease (CD). Traditional medication for IBD treatment involves the use of aminosalicylates, corticosteroids, thiopurines, folic acid antagonists, or biological treatments which only controls inflammation besides healing disease so that patients become intolerant to these remedies. Fecal microbiota transplantation (FMT) and probiotics have been discovered as promising candidates to re-create microbial balance in several immune-mediated illnesses such as IBD ${ }^{52}$. An analysis involving the treatment consequence of FMT and probiotic mixture VSL\#3 the clinical amnesty and medical response did not fluctuate much $^{51}$. The exact mechanism of effectiveness of FMT and the specific strains that confer this advantage remain undecided. It is stated that endoscopic FMT might be the first line to cure patients with severe CDI and its complications ${ }^{53}$.

Table 1. Diseases treated with FMT

\begin{tabular}{|c|c|c|c|}
\hline No. & Disorder/ Disease & Symptoms & Ref. \\
\hline \multirow[t]{4}{*}{1} & Metabolic diseases & Fatness/Obesity & 59,60 \\
\hline & & Metabolic syndrome & 59 \\
\hline & & Type 2 diabetes & 60,61 \\
\hline & & Insulin resistance & 61,62 \\
\hline \multirow[t]{2}{*}{2} & Liver diseases & $\begin{array}{l}\text { Alcoholic liver disease \&Non-alcoholic } \\
\text { fatty liver disease }\end{array}$ & 60,63 \\
\hline & & Chronic hepatitis B & 64 \\
\hline \multirow[t]{6}{*}{3} & Neuropsychiatric disorders & Parkinson's disease (PD) & 41 \\
\hline & & Alzheimer's disease (AD) & 65 \\
\hline & & Depression \& Multiple sclerosis (MS) & 65 \\
\hline & & Autism & 65 \\
\hline & & Chronic fatigue syndrome (CFS) & 66 \\
\hline & & Epilepsy & 65 \\
\hline \multirow[t]{2}{*}{4} & Autoimmune Disease & Idiopathic thrombocytopenic purpura & 67 \\
\hline & & Arthritis & 65,6 \\
\hline 5 & Cardiovascular disease & Myocarditis & 65,68 \\
\hline 6 & Kidney diseases & & 65 \\
\hline \multirow[t]{3}{*}{7} & Intestinal disorders & Inflammatory bowel diseases (IBD) & 69 \\
\hline & & Crohn's colitis & 70 \\
\hline & & Irritable Bowel Syndrome (IBS) & 71 \\
\hline
\end{tabular}


FMT not only consistently eradicates CDI but also reestablishes the Faecal flora, which is the possible mechanism for the pathogen's colonization and perseverance. In addition to CDI there are many other diseases which are treated by FMT (Table 1). After FMT treatment patients commonly experience symptoms like bloating, cramping, and/ or constipation after few days following transplant. FMTs performed via colonoscopy have certain consequences associated with colonoscopy, such as unfavorable tranquilizer reaction and bowel perforation after the procedure ${ }^{54}$. Probiotics are commonly administered in conjunction with antibiotics in order to replenish loss of normal flora. Oral administration of probiotics requires more time for normalization as compared to FMTs. There is a metabolic interconnection between the different microbial communities in gut to alleviate host immunity against pathogens. In this regard many physicians use a few individual species of 'excellent microorganisms' to treat antibioticinduced acute dysbiosis ${ }^{49}$. Probable mechanisms for FMT efficacy in treatment of CDI, comprises direct battle of $C$. difficile with commensal microbiota delivered by FMT, rebuilding of secondary bile acid metabolism in the colon and restoration of the gut barrier by stimulus of the mucosal immune system ${ }^{55}$. In a controlled study an industrial preparation (Bio-25) available in market containing 11 species of common probiotic bacteria (variety of Lactobacilli, Bifidobacteria, Lactococcus lactis, and Streptococcus thermophilus) was fed daily to healthy human volunteers for 28 days. The fed probiotic bacteria were discovered in stool samples of all members until they were using the product ${ }^{56}$ which led to a assumption that probiotics can be hypothetical target in FMT to boost the effectiveness of therapy. Oral administration of probiotic species Lactobacillus and Bifidobacterium for four to twelve weeks showed to be effective in treating constipation in Parkinsons Disease (PD) ${ }^{57}$.

Analysis of microbes in FMT showed abundant number of genera, Bacteroides, Prevotella, Bifidobacterium, Faecalibacterium, and Lachnospiraceae present along with Escherichia, Shigella and Alistipes ${ }^{58,46}$. Gut mucosal establishment of probiotics depends on the capability of probiotics to interact with local microbiome niches, which differ in their physiological properties along the gastrointestinal tract of the individual hence probiotics might solely be used in FMT. FMT provides number of microbes. Further research is needed on microbes and their products responsible for its health benefits. In addition to CDI there are many diseases which are treated by FMT.

\section{Vitamin production}

Probiotic bacteria have a positive effect on the immune system and the composition and operation of the gut microbiota ${ }^{11}$. Human beings are unable to make riboflavin or vitamin B2 and fulfill it from dietary intake of milk and dairy products, fish and meat. Riboflavin deficiency is indigenous in populations who are vegetarian, lacking dairy products and meat ${ }^{72}$. The Probiotic lactic acid bacteria $L$. lactis flourish in absence of riboflavin. Based on the genome sequencing of L. lactis IL1403, it is shown to harbour all genes required for riboflavin biosynthesis (rib genes) ${ }^{73}$. These micronutrients are used as a cofactor in several enzymatic reactions, as in case of vitamin $\mathrm{B} 12^{74}$. L. coryniformis subsp. coryniformis CRL 1001 can manufacture corrinoids with cobalamin action. HPLC and mass spectrometry analysis shows corrinoid produced is pseudo-cobalamin that has adenine like Co $\alpha$-ligand instead 5, 6-dimethylbenzimidazole. This molecule is one of the forms of coenzyme B12 occurring in atmosphere ${ }^{75}$. Vitamin B1 or Thiamine plays a significant role in amino acid metabolism, and is a rate limiting cofactor in production of neurotransmitter like dopamine, serotonin, gamma amino butyric acid (GABA), noradrenaline, and the hormone melatonin ${ }^{72,76}$. The strains of Lactobacillus used in production of functional foods belong to the species $L$. acidophilus, L. casei, L. paracasei, L. plantarum, L. reuteri, and L. salivarius which are powerful folic acid producers $^{8}$. Folic acid plays an important role in purines and pyrimidines metabolism, hence, in DNA formation. With exception to other lactic acid bacteria $L$. plantarum in presence of paraaminobenzoic acid (PABA) produces folic acid in vivo in rats.

Though abundant source of vitamin $\mathrm{K}$ are green leafy vegetables, some individuals are deficient in vitamin $\mathrm{K}$ which plays a major role in blood clotting. L. lactis ssp. cremoris (three strains), L. lactis ssp. lactis (two strains), and Leuconostoc 
lactis are high manufacturers of quinone that synthesize higher than $230 \mathrm{nmol}$ of quinones/g of dried cells ${ }^{77}$.

\section{Antibiofilm formation}

Biofilms are microbially derived immobile communities characteristic of cells that are adjacent to a substratum, an interface, or to each other; are embedded in a self-produced matrix; and display an altered phenotype with regard to growth rate and transcription profile ${ }^{78}$. Vibrio cholerae have ability to develop strong biofilms which is vital for its intestinal colonization ${ }^{79}$. This is for the reason that; biofilm forming cells are more efficient in competing for limiting nutrients in the small intestine. Probiotic strains having both antimicrobial and anti-biofilm properties against $V$. cholerae are anticipated to be clinically better. Culture supernatant of Faecal lactobacilli isolates prevent the adherence of both $V$. cholerae and $V$. parahaemolyticus to the colonic epithelial cell line HCT-15 by more than $90 \%{ }^{80}$. EPS-producing L. plantarum WLPL04 screened from human breast milk acquire anti-adhesion characteristic and ability to displace, and inhibit E. coli O157, $\mathrm{H} 7$, P. aeruginosa CMCC10104, S. typhimurium ATCC13311, and S. aureus CMCC26003. This indicates that EPS secreted by L. plantarum WLPL04 possesses activity against biofilm formed by pathogen ${ }^{81}$.

\section{Anti-obesity Properties}

The population of overweight people is increasing worldwide. Obesity is one of the defined health troubles and is considered as the most predominant form of malnutrition ${ }^{82}$, which increases the frequency of obesityrelated complications and the global problem of illness. Obesity is defined as an accumulation of unnecessary fat that weakens health. Excessive intake of calories is responsible for chronic diseases like obesity, gallbladder disease, coronary heart disease (CHD), hypertension, osteoarthritis (OA), type 2 diabetes mellitus, hyperlipidaemia, certain cancers and cardiovascular diseases ${ }^{83}$. The gut microbiota provides a powerful route that influences human health. In particular, polysaccharides and high fibre diet serve as primary modulators of the composition and role of the microbiota. The gut microbiota has been proposed as another factor involved in the onset of obesity. In a cohort study of 87 obese children and 57 healthy children, comparison of overall Faecal microbiota in obese children did not show variability in community diversity and richness ${ }^{84}$. Probiotics exhibiting Bile salt hydrolase (BSH) activity can result in reduced bodyweight, also lower levels of plasma cholesterol and liver triglycerides concentration ${ }^{85}$. The antiobesity consequence of probiotic dark tea was assessed in high-fat diet fed Sprague-Dawley (SD) rats. Probiotic dark tea lowered the body weight rise, serum triglycerol levels and serum total glycerol levels in extraordinary fat diet SD rats $^{86}$. It is also shown that obesity is linked with increased Firmicutes, while the concentration of Bacteroidetes is reduced in obese patients ${ }^{87}$. Obesity is associated with differentiation of preadipocytes to adipocytes which is examined by Lipid O staining. L. plantarum $\mathrm{K} 10$ isolated from homemade Kimchi showed $32.61 \%$ reduction in lipid accumulation compared to control. Freeze dried cultures of $L$. plantarum K10 fed to mice for 12 weeks demonstrated substantial drop in body weight as contrasted to high fat diet group ${ }^{88}$. One of the approaches of probiotics employing antiobesity activity is inhibition of intestinal lipid absorption by exerting lipase inhibition. L. casei Q180 strain of human origin displayed a lipase repressive activity of $83.61 \pm 2.31 \%$ compared to control and prevention of adipocyte differentiation of 3T3-L1 cells ${ }^{89}$. Lactobacillus curvatus HY7601 and Lactobacillus plantarum KY1032 given alone or in mixture for 9 weeks to mice were found to limit fat buildup in adipose tissue and liver ${ }^{90}$. Many clinical trials proved use of probiotics in controlling obesity as shown in Table 2. Thus, probiotics not only play a positive role in physiology of the host but also plays a modulatory role in obesity. Probiotics have been shown to influence the gut composition, improve gut integrity and restore the normal flora disturbance which leads to obesity.

\section{CONCLUSION}

Probiotics are known since from ancient times. The health benefits of probiotics discussed here are vitamin biosynthesis, antiobesity and antibiofilm property. Probiotics are the organisms residing in our intestinal tract. If an imbalance occurs in these microbes it leads to a diseased condition. These gut bacteria are responsible for digestion, absorption of nutrients; thus, 
Table 2. Clinical trials of probiotics in treatment of obesity

\begin{tabular}{|c|c|c|c|c|}
\hline Type of Study & Probiotic strain & $\begin{array}{l}\text { Duration of } \\
\text { study }\end{array}$ & Key findings & Ref. \\
\hline $\begin{array}{l}\text { Randomized, } \\
\text { double-blind, } \\
\text { placebo-controlled }\end{array}$ & $\begin{array}{l}\text { L. plantarum } \\
\text { TENSIA; } 8.7 \text { log } \\
\text { CFU per g }\end{array}$ & 3 weeks & $\begin{array}{l}\text { decreased BMI \& } \\
\text { hypertension }\end{array}$ & 91 \\
\hline $\begin{array}{l}\text { Randomized, } \\
\text { double-blind, } \\
\text { placebo-controlled }\end{array}$ & $\begin{array}{l}\text { L. gasseri BNR17 } \\
10^{9}-10^{10} \mathrm{CFU} / \text { day }\end{array}$ & 12 weeks & $\begin{array}{l}\text { decreased Visceral fat, } \\
\text { adipose tissue weight }\end{array}$ & 92 \\
\hline $\begin{array}{l}\text { placebo controlled, } \\
\text { randomized, and } \\
\text { double-blind }\end{array}$ & $\begin{array}{l}\text { L. gasseri BNR17 } \\
10^{10} \mathrm{CFU} / \text { day }\end{array}$ & 12 weeks & $\begin{array}{l}\text { decreased body } \\
\text { weight, waist } \\
\text { circumference }\end{array}$ & 92 \\
\hline $\begin{array}{l}\text { double-blinded, } \\
\text { randomized, } \\
\text { controlled }\end{array}$ & $\begin{array}{l}\text { Probiotic yoghurt } \\
\text { L. acidophilus La5 } \\
\text { \& B. lactis Bb12 } \\
300 \mathrm{~g} / \mathrm{d}\end{array}$ & 8 weeks & $\begin{array}{l}\text { decreased mean body } \\
\text { weight, BMI, serum } \\
\text { ALT and AST, total } \\
\text { cholesterol and LDL-C }\end{array}$ & 93 \\
\hline $\begin{array}{l}\text { randomized, } \\
\text { double-blind, } \\
\text { placebo-controlled }\end{array}$ & $\begin{array}{l}\text { L. urvatus } \mathrm{HY} 7601 \\
5 \times 10^{\circ} \mathrm{CFU} / \text { day } \\
\text { and } L \text {. plantarum } \\
\mathrm{KY} 10325 \times 10^{9} \mathrm{CFU} / \text { day }\end{array}$ & 12-week & $\begin{array}{l}\text { decreased Serum } \\
\text { Triglycerol }\end{array}$ & 94 \\
\hline $\begin{array}{l}\text { random, double- } \\
\text { blind, placebo- } \\
\text { controlled }\end{array}$ & $\begin{array}{l}\text { L. reuteri JBD301 } \\
450 \mathrm{mg} / \mathrm{d} \\
10^{9} \mathrm{CFU} / \text { capsule }\end{array}$ & 12 weeks & $\begin{array}{l}\text { decreased body } \\
\text { weight, intestinal FFA }\end{array}$ & 95 \\
\hline $\begin{array}{l}\text { multicenter, } \\
\text { double-blind, randomized, } \\
\text { placebo-controlled }\end{array}$ & $\begin{array}{l}\text { L. gasseri SBT2055 } \\
20 \mathrm{~g} / \mathrm{d}\end{array}$ & 12 weeks & $\begin{array}{l}\text { reduced abdominal visceral } \\
\text { and subcutaneous fat, body } \\
\text { weight, BMI, waist and hip } \\
\text { circumferences, body fat mass }\end{array}$ & 96 \\
\hline $\begin{array}{l}\text { randomized, } \\
\text { double-blind, } \\
\text { placebo-controlled } \\
\text { multicenter, } \\
\text { randomized, } \\
\text { double-blind, } \\
\text { placebo-controlled }\end{array}$ & $\begin{array}{l}\text { Bifidobacterium } \\
\text { breve B-3 } 5 \times 10^{10} \\
\text { CFU/ml } \\
\text { fermented milk } \\
\text { (FM) containing } B \text {. } \\
\text { lactis GCL2505 } 8 \\
\times 10^{10} \mathrm{CFU} / 100 \mathrm{~g}\end{array}$ & 12 weeks & decreased abdominal visceral fat & 97 \\
\hline $\begin{array}{l}\text { randomized, } \\
\text { double-blind, } \\
\text { placebo-controlled }\end{array}$ & $\begin{array}{l}\text { Yoghurt NY- } \\
\text { YP901 } \\
\text { Streptococcus } \\
\text { thermophilus, } \\
\text { L. acidophilus, B. } \\
\text { infantis \& B. breve } \\
\text { (CBG-C2), E. } \\
\text { faecalis FK-23 }\end{array}$ & 8 weeks & $\begin{array}{l}\text { decreased body weight and BMI } \\
\text { LDL-C }\end{array}$ & 99 \\
\hline $\begin{array}{l}\text { a randomized, } \\
\text { double-blind, } \\
\text { Placebo- crossover }\end{array}$ & $\begin{array}{l}\text { L. amylovorus } 1.39 \\
\times 10^{9} \mathrm{cfu} \text { and } L \text {. } \\
\text { fermentum } 1.08 \times \\
10^{9}\end{array}$ & $\begin{array}{l}\text { 43-day } \\
\text { phases }\end{array}$ & decreased body fat mass & 100 \\
\hline
\end{tabular}

ALT = alanine aminotransferase; $A S T=$ aspartate aminotransferase; $L D L-C=$ low-density lipoprotein cholesterol; $\mathrm{HDL}-\mathrm{C}=$ highdensity lipoprotein; BMI = Body mass index; SCFA, Short chain fatty acids; FFA = Free fatty acids. 
maintaining homeostasis. A healthy human gut microbiota contains higher ratio of Bacteroides to Firmicutes which change according to development stage, diet, antibiotic treatment, infections, and age. To replenish such disturbed flora, FMT and use of probiotics can be an option. Probiotic strain used must pass essential criteria as given by WHO/FAO. FMT is used effectively to cure different types of infections. The worldwide problem of obesity can be successfully treated with probiotics; is now clinically proven. Probiotics also boosts our immune system by synthesizing vitamins and antimicrobial compounds. In order to stay healthy a balance of gut microbiota by consuming probiotics needs to be maintained.

\section{ACKNOWLEDGMENTS}

We would like to thank Research Center, Haribhai V. Desai College, Pune affiliated to Savitribai Phule Pune University for providing necessary facilities to carry out above research work.

\section{CONFLICT OF INTEREST}

The authors declare that there is no conflict of interest.

\section{AUTHORS' CONTRIBUTION}

All authors listed have made a substantial, direct and intellectual contribution to the work, and approved it for publication.

\section{FUNDING}

None.

\section{DATA AVAILABILITY}

All datasets generated or analyzed during this study are included in the manuscript.

\section{ETHICS STATEMENT}

Not applicable.

\section{REFERENCES}

1. Hill C, Guarner F, Reid G, et al. The International Scientific Association for Probiotics and Prebiotics consensus statement on the scope and appropriate use of the term probiotic. Nat Rev Gastroenterol Hepatol. 2014;11(8):506-514. doi: 10.1038/nrgastro.2014.66

2. Falk PG, Hooper LV, Midtvedt T, Gordon JI. Creating and Maintaining the Gastrointestinal Ecosystem: What We Know and Need to Know from Gnotobiology. Microbiol
Mol Biol Rev.1998;62(4):1157-1170. doi: 10.1128/ MMBR.62.4.1157-1170.1998

3. Eckburg PB, Elisabeth MB, Charles NB, et al. Diversity of the Human Intestinal Microbial Flora. Science. 2005;308(5728):1635-1638. doi: 10.1126/ science.1110591

4. Khachatryan ZA, Ktsoyan ZA, Manukyan GP, Kelly D, Ghazaryan KA, Aminov RI. Predominant Role of Host Genetics in Controlling the Composition of Gut Microbiota. PloS One. 2008;3(8):e3064. doi: 10.1371/ journal.pone.0003064

5. Fagoonee S, Pellicano R. Does the microbiota play a pivotal role in the pathogenesis of irritable bowel syndrome? J Clin Med. 2019;8(11):1808.

6. Korotyki O, Vovk A, Galenova T, et al. Effect of probiotic on serum cytokines and matrix metalloproteinases profiles during monoiodoacetate-induced osteoarthritis in rats. Minerva Biotecnol. 2019;31(2):6873. doi: 10.23736/S1120-4826.19.02548-5

7. Zhang Y-J, Li S, Gan R-Y, Zhou T, Xu D-P, Li H-B. Impacts of Gut Bacteria on Human Health and Diseases. Int J Mol Sci. 2015;16(4):7493-7519. doi: 10.3390/ ijms16047493

8. Knight D, Ala'Aldeen D, Bengmark S, Girling K. The effect of synbiotics on gastrointestinal flora in the critically ill. Br J Anaesth. 2004;92:307-308.

9. Valerio F, De Bellis P, Lonigro SL, Morelli L, Visconti A, Lavermicocca P. In Vitro and In Vivo Survival and Transit Tolerance of Potentially Probiotic Strains Carried by Artichokes in the Gastrointestinal Tract. Appl Environ Microbiol. 2006;72(4):3042-3045.doi: 10.1128/ AEM.72.4.3042-3045.2006

10. Harish K, Varghese T. Probiotics in humans evidence-based review. Calicut Medical Journal. 2006;4(4):e3.https://www.researchgate.net/ publication/26496850_Probiotics_in_humanevidence_based_review. Accessed on 12 March 2021

11. FAO/WHO, Health and nutritional properties of probiotics in food including powder milk with live lactic acid bacteria, In, Report of a Joint FAO/WHO Expert Consultation on Evaluation of Health and Nutritional Properties of Probiotics in Food including Powder Milk with Live Lactic Acid Bacteria, Cordoba, Argentina. WHO, Geneva, Switzerland. 2001:1-34.

12. Tuomola E, Crittenden R, Playne M, Isolauri E, Salminen S. Quality assurance criteria for probiotic bacteria. Am J Clin Nutr. 2001;73(2):393S-398S. doi: 10.1093/ ajcn/73.2.393s

13. Begley M, Gahan CGM, Hill C. The interaction between bacteria and bile. FEMS Microbiol Rev. 2005;29(4):625651. doi: 10.1016/j.femsre.2004.09.003

14. Kim G, Lee BH. Biochemical and Molecular Insights into Bile Salt Hydrolase in the Gastrointestinal Microflora A Review. Asian-Australian Journal of Animal Sciences. 2005;18(10):1505-1512. doi: 10.5713/ajas.2005.1505

15. Patel AK, Singhania RR, Pandey A, Chincholkar SB. Probiotic Bile Salt Hydrolase: Current Developments and Perspectives. Appl Biochem Biotechnol. 2010;162(1):166-180. doi: 10.1007/s12010-009-87381

16. Chand D, Panigrahi P, Varshney N, Ramasamy S, Suresh 
SG. Structure and function of a highly active Bile Salt Hydrolase (BSH) from Enterococcus faecalis and posttranslational processing of BSH enzymes. BBA-Proteins and Proteomics. 2018;1866(4):507-518. doi: 10.1016/j. bbapap.2018.01.003

17. Istiqomah L, Anwar M, Anggraeni AS, Damayanti E. Cholesterol assimilation of Saccharomyces cerevisiae B-18 isolated from gastrointestinal tract of Javanese duck. J Indones Trop Anim Agric. 2018;43(2):149-158. doi: 10.14710/jitaa.43.2.149-158

18. Zhang F, Qiu L, Xu X, et al. Beneficial effects of probiotic cholesterol-lowering strain of Enterococcus faecium WEFA23 from infants on diet-induced metabolic syndrome in rats. J Dairy Sci. 2017;100(3):1618-1628. doi: 10.3168/jds.2016-11870

19. Waddington L, Cyr T, Hefford M, Hansen LT, Kalmokoff $M$. Understanding the acid tolerance response of bifidobacteria. J Appl Microbiol. 2010;108(4):14081420. doi: 10.1111/j.13652672.2009. 04540.x

20. Noriega L, Gueimonde M, Sanchez B, Margolles A, de los Reyes-Gavilan CG. Effect of the adaptation to high bile salts concentrations on glycosidic activity, survival at low $\mathrm{pH}$ and cross-resistance to bile salts in Bifidobacterium. Int J Food Microbiol. 2004;94(1):7986. doi: 10.1016/j.ijfoodmicro.2004.01.003

21. Matsumoto $\mathrm{M}$, Ohishi $\mathrm{H}$, Benno $\mathrm{Y}$. $\mathrm{H}^{+}$-ATPase activity in Bifidobacterium with special reference to acid tolerance. Int J Food Microbiol. 2004;93(1):109-113. doi: 10.1016/j.ijfoodmicro.2003.10.009

22. Tejero-Sarinena S, Barlow J, Costabile A, Gibson GR, Rowland I. In vitro evaluation of the antimicrobial activity of a range of probiotics against pathogens, Evidence for the effects of organic acids. Anaerobe. 2012;18(5):530-538. doi: 10.1016/j. anaerobe.2012.08.004

23. Kralik P, Babak V, Dziedzinska R. The Impact of the Antimicrobial Compounds Produced by Lactic Acid Bacteria on the Growth Performance of Mycobacterium avium subsp. Paratuberculosis. Front Microbiol. 2018;(9):638. doi: 10.3389/fmicb.2018.00638

24. Hor YY, Liong MT. Use of extracellular extracts of lactic acid bacteria and bifidobacteria for the inhibition of dermatological pathogen Staphylococcus aureus. Dermatologica Sinica. 2014;32(3):141-147. doi: 10.1016/j.dsi.2014.03.001

25. Saavedra JM. Clinical applications of Ptobiotic agents. Am J Clin Nutr. 2001;73(6):1147s-1151s. doi: 10.1093/ ajcn/73.6.1147S

26. Di Pierro F, Bertuccioli A, Saponara M, Ivaldi L. Impact of a two-bacterial-strain formula, containing Bifidobacterium animalis lactis BB-12 and Enterococcus faecium L3, administered before and after therapy for Helicobacter pylori eradication. Minerva Gastroenterol Dietol. 2020;66:117-123. doi: 10.23736/S1121421X.19.02651-5

27. Saint-Cyr MJ, Guyard-Nicodeme M, Messaoudi S. et al. Recent Advances in Screening of Anti-Campylobacter Activity in Probiotics for Use in Poultry. Front Microbiol. 2016;7:553. doi: 10.3389/fmicb.2016.00553

28. Roya VS, Rouha KK, Maliheh S, Ghadam P, Feizabadi MM, Teimourian S. Antagonistic activities of some probiotic lactobacilli culture supernatant on Serratia marcescens swarming motility and antibiotic resistance. Iran J Microbiol. 2017;9(6):348-355. https://pubmed.ncbi. nlm.nih.gov/29487733/. Accessed 11 March 2021.

29. Chelliaha R, Choi J, Hwanga $S$, et al. In vitro and in vivo defensive effect of probiotic $L A B$ against Pseudomonas aeruginosa using Caenorhabditis elegans model. Virulence. 2018;9(1):1489-1507. doi: 10.1080/21505594.2018.1518088

30. Lehto EM, Salminen S. Adhesion of two Lactobacillus strains, one Lactococcus and one Propionibacterium strain to cultured human intestinal Caco-2 cell line. Biosci Microflora. 1997;16(1):13-17. doi: 10.12938/ bifidus1996.16.13

31. Tuomola EM, Ouwehand AC, Salminen SJ. Human ileostomy glycoproteins as a model for small intestinal mucus to investigate adhesion of probiotics. Lett Appl Microbiol. 1999;28(3):159-163. doi: 10.1046/j.13652672.1999.00518.x

32. Collado $M C$, Gueimonde $M$, Sanz $Y$, Salminen $S$. Adhesion properties and competitive pathogen exclusion ability of Bifidobacteria with acquired acid resistance. J Food Pro. 2006;69 (7):1675-1679. doi: 10.4315/0362-028x-69.7.1675

33. Zarate $G$, Nader-Macias ME. Influence of probiotic vaginal lactobacilli on in vitro adhesion of urogenital pathogens to vaginal epithelial cells. Lett Appl Microbiol. 2006;43(2):174-180. doi: 10.1111/j.1472765X.2006.01934.X

34. Banerjee P, Merkel G, Bhunia A. Lactobacillus delbrueckii ssp. bulgaricus B-30892 can inhibit cytotoxic effects and adhesion of pathogenic Clostridium difficile to Caco-2 cells. GutPathogens. 2009;1:8. doi: 10.1186/1757-4749-1-8

35. Tareb R, Bernardeau M, Gueguen M, Vernoux J-P. In vitro characterization of aggregation and adhesion properties of viable and heat-killed forms of two probiotic Lactobacillus strains and interaction with food borne zoonotic bacteria, especially Campylobacter jejuni. J Med Microbiol. 2013;62(4):637-649. doi: 10.1099/jmm.0.049965-0

36. Collado MC, Meriluoto J, Salminen S. Measurement of aggregation properties between probiotics and pathogens: In vitro evaluation of different methods. J Microbiol Methods. 2007;71(1):71-74. doi: 10.1016/j. mimet.2007.07.005

37. Cummings JH, Macfarlane GT. Gastrointestinal effects of prebiotics. Br J Nutr. 2002;87(Suppl. 2):S145-S151. doi: 10.1079/BJNBJN/2002530

38. Gueimonde M, Sanchez B, de los Reyes-Gavilan CG, Margolles A. Antibiotic resistance in probiotic. Front Microbiol. 2013;4:202. doi: 10.3389/fmicb.2013.00202

39. Stanton C, Gardiner G, Meehan H, et al. Market potential for probiotics. Am J Clin Nutr. 2001;73(2):476483. doi: $10.1093 / \mathrm{ajcn} / 73.2 .476 \mathrm{~s}$

40. Laulund S, Anette W, Derkx PMF, Zuliani V. Regulatory and Safety Requirements for Food Cultures. Microorganisms. 2017;5(2):28. doi: 10.3390/ microorganisms5020028

41. Parashar A, Udayabanu M. Gut microbiota, Implications in Parkinson's disease. Parkinsonism Relat Disord. 
2017;38:1-7. doi: 10.1016/j.parkreldis.2017.02.002

42. Donaldson GP, Lee SM, Mazmanian SK. Gut biogeography of the bacterial microbiota. Nat Rev Microbiol. 2016;14(1):20-32. doi: 10.1038/ nrmicro3552

43. Xu C, Zhu H, Qiu P. Aging progression of human gut microbiota. BMC Microbiology. 2019;19:236. doi: 10.1186/s12866-019-1616-2

44. Borody TJ, Paramsothy S, Agrawal G. Fecal microbiota transplantation, indications, methods, evidence, and future directions. Curr Gastroenterol Rep. 2013;15(8):337. doi: 10.1007/s11894-013-0337-1

45. Borody TJ, Clancy A. Fecal microbiota transplantation for ulcerative colitis-where to from here? Transl Gastroenterol Hepatol. 2019;5:48. doi: 10.21037/ tgh.2019.06.04

46. Ott SJ, Waetzig GH, Rehman A, et al. Efficacy of Sterile Fecal Filtrate Transfer for Treating Patients with Clostridium difficile Infection. Gastroenterol. 2017;152(4):799-811. doi: 10.1053/j. gastro.2016.11.010

47. Rosenbaum M, Knight R, Leibel RL. The gut microbiota in human energy homeostasis and obesity. Trends Endocrinol Metab. 2015;26(9):493-501. doi: 10.1016/j. tem.2015.07.002

48. Lessa FC, Winston LG, McDonald LC. Emerging Infections Program CdST. Burden of Clostridium difficile infection in the United States. $N$ Engl J Med. 2015;372(24):2369-2370. doi: 10.1056/ NEJMc1505190

49. Surawicz CM, McFarland LV. Pseudomembranous Colitis Causes and Cures. Digestion. 1999;60(2):91100. doi: $10.1159 / 000007633$

50. Mcilroy JR, Segal JP, Mullish BH, et al. Current and future targets for faecal microbiota transplantation. Hum Microb J. 2019;11:100045. doi: 10.1016/j. humic.2018.08.004

51. Dang X, Xu M, Liu D, Zhou D, Yang W. Assessing the efficacy and safety of Fecal microbiota transplantation and probiotic VSL\#3 for active ulcerative colitis, A systematic review and meta-analysis. PLOS ONE. 2020;15(3):e0228846. doi: 10.1371/journal. pone. 0228846

52. Basso PJ, Saraiva Camara NO, Sales-Campos H. Microbial-Based Therapies in the Treatment of Inflammatory Bowel Disease - An Overview of Human Studies. Fron Pharmacol. 2019;9:1571. doi: 10.3389/ fphar.2018.01571

53. Brandt LJ, Borody TJ, Campbell J. Endoscopic Fecal Microbiota Transplantation "First-Line" Treatment for Severe Clostridium difficile Infection? Clin J Gastroenterol. 2011;45(8):655-657. doi:10.1097/ MCG.0b013e3182257d4f

54. Tauxe WM, Dhere T, Ward AD, Racsa LD, Varkey JB, Kraft CS. Fecal Microbiota Transplant Protocol for Clostridium Difficile Infection. Lab Med. 2015;46(1):1923. doi: 10.1309/LMCI95MOTWPDZKOD

55. Khoruts A, Sadowsky MJ. Understanding the mechanisms of faecal microbiota transplantation. Nat Rev Gastroenterol Hepatol. 2016;13(9):508-516. doi: 10.1038/nrgastro.2016.98
56. Zmora N, Zilberman-Schapira G, Suez J, et al. Personalized gut mucosal colonization resistance to empiric probiotics is associated with unique host and microbiome features. Cell. 2018;174(6):1388-1405. doi: 10.1016/j.cell.2018.08.041

57. Cassani E, Privitera G, Pezzoli G. et al. Use of probiotics for the treatment of constipation in Parkinson's disease patients. Minerva Gastroenterol Dietol. 2011;57(2):117-121. https://europepmc.org/article/ med/21587143. Accessed March 08, 2021

58. Papanicolas LT, Choo JM, Wang Y, et al. Bacterial viability in Faecal transplants, Which bacteria survive? EBiomedicine. 2019;41:509-516. doi: 10.1016/j. ebiom.2019.02.023

59. Zhang Z, Mocanu V, Cai C, et al. Impact of Faecal Microbiota Transplantation on Obesity and Metabolic Syndrome A Systematic Review. Nutrients. 2019;11(10):221. doi: 10.3390/nu11102291

60. Sarin SK, Pande A, Schnab B. Microbiome as a therapeutic target in alcohol-related liver disease. J Hepatol. 2019;70(2):260-272. doi: 10.1016/j. jhep.2018.10.019

61. Wang H, Lu Y, Yan Y, et al. Promising Treatment for Type 2 Diabetes, Fecal Microbiota Transplantation Reverses Insulin Resistance and Impaired Islets. Front Cell Infect Microbiol. 2020;9:455. doi: 10.3389/fcimb.2019.00455

62. de Groot PF, Frissen MN, deClercq NC, et al. Fecal microbiota transplantation in metabolic syndrome, history, present and future. Gut Microbes. 2017;8:253267. doi: 10.1080/19490976.2017.1293224

63. Cassard A, Ciocan D. Microbiota, a key player in alcoholic liver disease. Clin Mol Hepatol. 2018;24(2):100-107. doi: 10.3350/cmh.2017.0067

64. Liu $Q$, Li F, Zhuang $\mathrm{Y}$, et al. Alteration in gut microbiota associated with hepatitis $B$ and non-hepatitis virus related hepatocellular carcinoma. Gut Pathog. 2019;11:1. doi: 10.1186/s13099-018-0281-6

65. Zhou $\mathrm{Y}, \mathrm{Xu} \mathrm{H}$, Huang $\mathrm{H}$, et al. Are There Potential Applications of Fecal Microbiota Transplantation beyond Intestinal Disorders? Biomed Res Int. 2019;2019:3469754. doi: 10.1155/2019/3469754

66. Borody TJ, Nowak A, Finlayson S. The GI microbiome and its role in Chronic Fatigue Syndrome, A summary of bacteriotherapy. Australasian College of Nutritional and EnvironmentalMedicine.2012;31:3-8. https://www. scirp.org/(S(czeh2tfqyw2orz553k1w0r45))/reference/ ReferencesPapers.aspx? ReferencelD $=2023276$ Accessed on 12 March 2021.

67. Xu M, Cao $\mathrm{H}$, Wang $\mathrm{W}$, et al. Fecal microbiota transplantation broadening its application beyond intestinal disorders. World J Gastroenterol. 2015;21(1):102-111.doi: 10.3748/wjg.v21.i1.102

68. Leshem A, Horesh N, Elinav E. Fecal Microbial Transplantation and Its Potential Application in Cardiometabolic Syndrome. Front Immunol. 2019;10:1341. doi: 10.3389/fimmu.2019.01341

69. Sunkara T, Rawla P, Ofosu A, Gaduputi V. Fecal microbiota transplant - a new frontier in inflammatory bowel disease. J Inflamm Res. 2018;11:321-328. doi: 10.2147/JIR.S176190

70. Bak S, Choi H, Lee J, et al. Fecal microbiota 
transplantation for refractory Crohn's disease. Intest Res. 2017;15(2):244-248. doi: 10.5217/ ir.2017.15.2.244

71. Shaukat A, Brenner D. Fecal Microbiota Transplant for Irritable Bowel Syndrome, Panacea or Placebo? Am J Gastroenterol. 2019;114(7):1032-1033. doi: 10.14309/ ajg.0000000000000259

72. Powers HJ. Riboflavin (vitamin B-2) \& health. Am J Clin Nutr. 2003;77(6):1352-1360. doi: 10.1093/ ajcn/77.6.1352

73. Bolotin A, Wincker P, Mauger S, et al. The complete genome sequence of the lactic acid bacterium Lactococcus lactis ssp. lactis IL1403. Genome Res. 2001;11(5):731-753. doi: 10.1101/gr.gr-1697r

74. Martens JH, Barg H, Warren MJ, Jahn D. Microbial production of vitamin B12. Appl Microbiol Biotechnol. 2002;58(3):275-285. doi: 10.1007/s00253-001-0902-7

75. Torrece AC, Vannini V, Bonacina J, Font G, Saavedra L, Taranto MP. Cobalamin production by Lactobacillus coryniformis, biochemical identification of the synthetized corrinoid and genomic analysis of the biosynthetic cluster. BMC Microbiol. 2016;16:240. doi: 10.1186/s12866-016-0854-9

76. Kerns JC, Arundel C, Chawla LS. Thiamin deficiency in people with obesity. Adv Nutr. 2015;6(2):147-153. doi: 10.3945/an.114.007526

77. Morishita T, Tamura N, Makino T, Kudo S. Production of menaquinones by lactic acid bacteria. J Dairy Sci. 1999;82(9):1897-1903. doi: 10.3168/jds.S00220302(99)75424-X

78. Donlan RM, Costerton JW. Biofilms, survival mechanisms of clinically relevant microorganisms. Clin Microbiol Rev. 2002;15(2):167-93. doi: 10.1128/ cmr.15.2.167-193.2002

79. Silva AJ, Benitez JA. Vibrio cholerae biofilms and cholera pathogenesis. PLoS Negl Trop Dis. 2016;10(2):e0004330. doi: 10.1371/journal. pntd.0004330

80. Kaur S, Sharma P, Kalia N, Singh J, Kaur S. Antibiofilm properties of Fecal probiotic Lactobacilli against Vibrio spp. Front Cell Infect Microbiol. 2018;8:120. doi: 10.3389/fcimb.2018.00120

81. Liu Z, Zhang Z, Qiu L, et al. Characterization and bioactivities of the exopolysaccharide from a probiotic strain of Lactobacillus plantarum WLPL04. J Dairy Sci. 2017;100(9):6895-6905. doi: 10.3168/jds.2016-11944

82. Ma X, Chena $Q$, Pua $Y$, et al. Skipping breakfast is associated with overweight and obesity, A systematic review and meta-analysis. Obes Res Clin Pract. 2020;14(1):1-8. doi: 10.1016/j.orcp.2019.12.002

83. Popkin BM, Hawkes C. The sweetening of the global diet, particularly beverages, patterns, trends and policy responses. Lancet Diabetes Endocrinol. 2016;4(2):174186. doi: 10.1016/S2213-8587(15)00419-2

84. Hou $\mathrm{Y}, \mathrm{He} \mathrm{Q}$, Ouyang $\mathrm{H}$, et al. Human Gut Microbiota Associated with Obesity in Chinese Children and Adolescents. Biomed Res Int. 2017;2017:7585989. doi: 10.1155/2017/7585989

85. Cani PD, Hul MV. Novel opportunities for nextgeneration probiotics targeting metabolic syndrome. Curr Opin Biotechnol. 2015;32:21-27. doi: 10.1016/j. copbio.2014.10.006

86. Ling W, Li S, Zhang X, et al. Evaluation of Anti-Obesity Activity, Acute Toxicity, and Subacute Toxicity of Probiotic Dark Tea. Biomolecules. 2018;8(4):99.doi: 10.3390/biom8040099

87. Million M, Lagier JC, Yahav D, Paul M. Gut bacterial microbiota and obesity. Clin Microbiol Infect. 2013;19:305-313. doi: 10.1111/1469-0691.12172

88. Kim J, Yun JM, Kim MK, Kwon O, Cho B. Lactobacillus gasseri BNR17 Supplementation Reduces the Visceral Fat Accumulation and Waist Circumference in Obese Adults, A Randomized, Double-Blind, PlaceboControlled Trial. J Med Food. 2018;21(5):454-461. doi: 10.1089/jmf.2017.3937

89. Park S-Y, Cho S-A, Kim S-H, Lim S-D. Physiological Characteristics and Anti-obesity Effect of Lactobacillus plantarum Q180 Isolated from Feces. Korean J Food Sci Anim Resour. 2014;34(5):647-655. doi: 10.5851/ kosfa.2014.34.5.647

90. Brusaferro A, Cozzali R, Orabona C, et al. Is It Time to Use Probiotics to Prevent or Treat Obesity? Nutrients. 2018;10(11):1613. doi: 10.3390/nu10111613

91. Sharafedtinov KK, Plotnikova OA, Alexeeva IR, et al. Hypocaloric diet supplemented with probiotic cheese improves body mass index and blood pressure indices of obese hypertensive patients - a randomized double-blind placebo-controlled pilot study. I Nutr. 2013;12:138. doi: 10.1186/1475-2891-12-138

92. Jung SP, Lee KM, Kang JH, et al. Effect of Lactobacillus gasseri BNR17 on overweight and obese adults, a randomized, double-blind clinical trial. Korean J Fam Med. 2013;34(2):80-89. doi: 10.4082/ kjfm.2013.34.2.80

93. Nabavi S, Rafraf M, Somi MH, Homayouni-Rad A, Asghari-Jafarabadi M. Effects of probiotic yogurt consumption on metabolic factors in individuals with nonalcoholic fatty liver disease. J Dairy Sci. 2014;97(12):7386-7393. doi: 10.3168/jds.2014-8500

94. Ahn HY, Kim M, Ahn YT, et al. The triglyceridelowering effect of supplementation with dual probiotic strains, Lactobacillus curvatus HY7601 and Lactobacillus plantarum KY1032, Reduction of fasting plasma lysophosphatidylcholines in nondiabetic and hypertriglyceridemic subjects. Nutr Metab Cardiovasc Dis. 2015;25(8):724-733. doi: 10.1016/j. numecd.2015.05.002

95. Chung HJ, Yu JG, Lee IA, et al. Intestinal removal of free fatty acids from hosts by Lactobacilli for the treatment of obesity. FEBS Open Bio. 2016;6(1):64-76. doi: 10.1002/2211-5463.12024

96. Kadooka Y, Sato M, Imaizumi K, et al. Regulation of abdominal adiposity by probiotics (Lactobacillus gasseri SBT2055) in adults with obese tendencies in a randomized controlled trial. Eur J Clin Nutr. 2010;64(6):636-643. doi: 10.1038/ejcn.2010.19

97. Minami J, Kondo S, Yanagisawa N, et al. Oral administration of Bifidobacterium breve B-3 modifies metabolic functions in adults with obese tendencies in a randomised controlled trial. J Nutr Sci. 2015;4:e17. doi: 10.1017/jns.2015.5

98. Takahashi S, Anzawa D, Takami K, et al. Effect of 
Patil et al. | J Pure Appl Microbiol | 15(3):1111-1124| September 2021 | https://doi.org/10.22207/JPAM.15.3.53

Bifidobacterium animalis ssp. lactis GCL2505 on visceral fat accumulation in healthy Japanese adults, a randomized controlled trial. Biosci Microbiota Food Health. 2016;35(4):163-171. doi: 10.12938/ bmfh.2016-002

99. Chang BJ, Park SU, Jang YS, et al. Effect of functional yogurt NY-YP901 in improving the trait of metabolic syndrome. Eur J Clin Nutr. 2011;65(11):1250-1255. doi: 10.1038/ejcn.2011.115

100. Omar JM, Chan YM, Jones ML, Prakash S, Jonesa PJH. Lactobacillus fermentum and Lactobacillus amylovorus as probiotics alter body adiposity and gut microflora in healthy persons. J Funct Foods. 2013;5:116-123. doi: 10.1016/j.jff.2012.09.001 